<smiles>CC1(NC(=O)O)C(=O)N[C@@H](C(=O)O)C1(C)C</smiles>

though the exact form of the chelate and strength of the ligand has not been determined. Penicillamine has an affinity for many metals, but its main clinical usefulness is so far confined to removal of copper from patients with Wilson's disease, in which it is a highly effective form of treatment, ${ }^{8}$ and for treatment of both lead and mercury poisoning, though for the latter $\mathrm{N}$-acetyl penicillamine may be preferable. For patients with Wilson's disease the dose varies between $500 \mathrm{mg}$ of free base (or $600 \mathrm{mg}$ of the hydrochloride) three times a day and $1,000 \mathrm{mg}$ three times a day. It is seldom necessary or wise to give a dose above $2 \mathrm{~g}$ a day for more than a year.

In lead poisoning penicillamine may be given by mouth in similar doses for adults or correspondingly less for children. 910 For very severe lead poisoning with encephalopathy intravenous penicillamine has been found as effective as intravenous EDTA. In Wilson's disease the drug must be continued for life, but in lead poisoning the dose must be controlled by reference to the excretion of lead and of deltaaminolaevulic acid in the urine. Penicillamine may be discontinued when the concentrations of these reach a low and steady level.

Penicillamine gives rise to several toxic reactions, ${ }^{11}$ the most serious being the nephrotic syndrome, though this is rare in patients with Wilson's disease; fortunately this is reversible once the drug is discontinued. It has also caused granulocytopoenia and leucopoenia, but, though these may be worrying, they seldom mean that treatment has to be stopped. Penicillamine antagonizes the action of pyridoxine but administration of $50 \mathrm{mg}$ of this vitamin weekly is more than enough to make good all requirements.

It has recently been suggested that penicillamine-intolerant patients with Wilson's disease, for whom the drug is lifesaving, can be managed with a new orally active chelating agent, triethylene tetramine. ${ }^{12}$ Nevertheless, this compound is not at present commercially available in a therapeutically acceptable form. In view of the rarity of this complication and the expense involved in getting a new drug accepted by the Committee on Safety of Drugs it seems unlikely that this compound-or for that matter any new therapy for a rare disease-will ever offer sufficient prospects of profit to be commercially viable.

1 Seven, M. J., and Johnson, L. A., Metal Binding in Medicine. Philadelphia, J. B. Lippincott, 1960

2 Peters, R. A., Stocken, L. A., and Thompson, R.H.S., Nature, 1945, 156, 616.

3 Bessman, S. P., Reid, H., and Rubin, M., Medical Annals of the District of Columbia, $1952,21,312$

Walshe, J. M., American fournal of Medicine, 1956, 21, 487.

5 Cumings, J. N. Brain, 1948, 71, 410.

6 Fielding, J., fournal of Clinical Pathology, 1965, 18, 88.

Fielding, J., Fournal of Clinical Pathology, 1967, 20, 668

8 Walshe, J. M., British fournal of Hospital Medicine, 1970, 4, 91.

Moncrieff, A., Koumides, O.P., Clayton, B.E., Patrick, A.D., and Renwick, A. G. C., Archives of Diseases of Childhood, 1964, 39, 1. Selander, S., Cramer. K., and Hallberg, L., British fournal of Industrial Medicine, 1966, 23, 282

11 Postgraduate Medical fournal, Supplement on penicillamine, 1968.

12 Walshe, J. M., Lancet, 1969, 2, 1401.

\title{
The Forgotten
}

\section{VIII-An Occupational Centre}

\author{
FROM A SPECIAL CORRESPONDENT
}

The occupational centre is on the outskirts of a southern market town, set among lawns, simply constructed, but custombuilt. The workrooms are bright and warm and all doors are wide enough to admit wheelchairs, though the lavatories should have been big enough to take a helper as well as a patient. Mr. P. Q., the supervisor, is an elderly enrolled nurse, kindly and tolerant, with a background of engineering experience and a great deal of mechanical ingenuity in devising and modifying equipment for disabled patients.

The purpose of an occupational centre is to give its clients something to do. The psychiatric and the mentally subnormal attend a separate centre but a certain amount of mental impairment is tolerated in Mr. P. Q.'s establishment-otherwise many old people would have to be excluded. People who are referred to the centre are in general those who cannot be expected to show any substantial physical improvement. Most are elderly and because of their longer life expectancy women predominate; the degenerative conditions such as stroke, arthritis, and heart disease are those most commonly seen. Young people form a small group with a poor prognosis, since if they are thought to have a fair chance of recovery they are dealt with under a rehabilitation scheme. The plight of these younger patients is sad and the supervisor tries to get them all in on the same day. He hopes to find an instructor capable of stimulating them and possibly finding ways in which they could rejoin the normal labour force.

\section{Successes and Strains}

A few successes are achieved by this age group though work obtained through the Department of Employment sometimes seems to Mr. P. Q. not entirely suited to his client. Information seems to be exchanged with some difficulty between departments and authorities concerned. Recently Mr. P. Q. was reproached for having placed an epileptic in a job associated with machinery. When he said he had never been told and did not know that the boy had epilepsy he was told that he could not expect to be given this kind of confidential information. Sometimes the hysterical or depressed regain old skills in this noncompetitive situation; sometimes, however, it seems that some might benefit from more dynamic surroundings. One patient was a young and attractive paraplegic hoping for a post as a receptionist-losing heart and putting on weight. It seemed to me that until she could learn to drive and obtain a car her hopes of employment were slight. 
Mr. P. Q. receives an application for a place with a form giving some particulars about the reasons for seeking occupation there, whether transport is needed, and what the toilet requisites are. He would welcome a little more information that would enable him to give more intelligent therapy-for instance, if there is anything the patient should not do. Some of his patients carry tablets for emergency use, but he does not know how the emergency is likely to present. There are 137 patients on the books, most of whom come for two days a week. At the moment there is a waiting list of eight and the chief bottleneck is transport. Those who have their own can be accommodated but most have to be fetched and taken home by ambulance. Patients tend to be faithful-one 90 -year-old woman has been coming regularly ever since the centre opened six years ago. Her alert mental condition is doubtless partly due to the company and contacts at the centre. Some patients are recommended to the centre because of social isolation, some to relieve their relatives for a few hours, some to see if there is any hope of recovery to the stage of being suitable for rehabilitation. The patients are given a little time to look round and make contact before they are asked what they would like to do, and indeed no effort is made with the elderly to induce them to do anything. Most of them do because the general atmosphere of activity is infectious. Perhaps the younger patients should not always be in the company of the old, but the presence of the young ones is certainly beneficial to the elderly. Many of the hemiplegics who arrive here, despondent and motiveless, realize when they see the young who are going to be handicapped for the whole of their lives that they themselves are more fortunate than they knew.

\section{Piecework}

The work produced by the elderly patients consists mostly of canework and coathangers. Mr. P. Q. buys supplies at wholesale prices and has no obligation to make a profit, so the patients can buy their materials at cost price, selling them for whatever they can get. Anything they earn, up to $£ 1.50$ a week, is disregarded in income assessment. Mr. P. Q. has modified many kinds of apparatus for his patients so that those who can use only one hand may do canework and those who cannot use their hands can type if they can use their minds. When he has men capable of doing carpentry he makes "Wendy" houses for children, which have a ready sale.

The people who are drawn to supervise the work in such centres have some characteristics in common. They tend to have withdrawn from commercial competition in workshop or factory because they lack the zest for rough-and-tumble, and in this environment they can extend compassion and help to people in need of it. Mr. P. Q. himself took up this work because his son is mentally retarded and this turned his thoughts to service rather than to economic success. Occupational centres are not a very prominent or dramatic part of the social services, nor do they contribute in any striking way to success statistics, but these are not the only criteria by which value is to be judged.

\section{Any Questions?}

We publish below a selection of questions and answers of general interest

\section{Reconstructed Nipple}

Is there any surgical means of reconstructing in an adolescent girl a nipple and mamillary ducts which were destroyed by burns in childhood, and could a functional as well as a cosmetic result be obtained?

It is possible to reconstruct a nipple. The exact technical nature of the repair depends on the local tissue available after, in this case, the burn. If the skin is sufficiently well healed a nipple can be reconstructed from local skin and then pigmented by tattooing. When there is extensive local scarring some type of graft may be required, and, indeed, even the umbilicus has been used to replace the nipple.

It is impossible to replace mamillary ducts and there is no question of any functional activity. Should pregnancy take place the residual breast tissue would be unable to discharge milk through the damaged nipple region and suppression of lactation would be required.

\section{Ants in the Bedroom}

What is the best way of exterminating ants in a nurse's bedroom in Britain?

The pest concerned is almost certainly Pharaoh's ant, Monomorium pharaonis, a tiny, yellowish tropical species, common in hospitals and other large centrally-heated buildings. These ants, which do not live out of doors in cool climates, nest in hollow spaces in the walls. Apart from being a nuisance, they could in some circumstances transmit pathogens, since they often visit moist or liquid substances for water and have been seen in drains, urinals, and similar undesirable places. Ants may travel to many parts of a heated building and set up secondary nests. They may invade laundry baskets, dressing stores, and even operating theatres.

Since the nests are concealed in the structure of the building, it is generally impossible to get at them and destroy them. Nevertheless, the first step is to trace the location of the nest (or nests) in order to concentrate control measures. This can be done by setting out small baits (scraps of raw meat or liver are very attractive) and tracing the ant trails back to their source.

When the location of the nest is ascertained the walls of the surrounding area are treated with a residual insecticide. Insecticidal lacquer is excellent. Alternatively an emulsion of $2 \%$ chlordane is applied by spray. Wall junctions, skirtings, surrounds of radiators, sinks, and built-in cupboards are mainly treated. It is possible to get this done by the hospital works staff, ${ }^{1}$ but generally speaking it is more satisfactory to call in a reliable pesticide servicing company.

For temporary protection until eradication is achieved it may be worth preventing the ants climbing up legs of beds, cots, or tables by smearing the legs with a concentrated insecticide or a good repellent.

1 Busvine, J. R., Insects and Hygiene, 2nd edn. London, Methuen, 1960. 